\title{
The use of chatbot as an element of tutorial action in university teaching
}

Pedro Ángel Castillo Valdivieso - Universidad de Granada

María del Carmen Aguilar Luzón - Universidad de Granada
0000-0002-5258-0620

0000-0001-9689-6283

Recepción: 25.05.2021 | Aceptado: 21.06.2021

Correspondencia a través de ORCID: María del Carmen Aguilar Luzón

0000-0001-9689-6283

Citar: Castillo Valdivieso, PA, \& Aguilar Luzon, MC (2021). The use of chatbot as an element of tutorial action in university teaching. REIDOCREA, 10(24), 1-14.

Funding sources: Ministerio Español de Economía y Competitividad - project TIN2017-85727-C4-2-P -UGR-DeepBio-

\begin{abstract}
It is of great importance to help and pay attention to students through different educational activities to ensure their participation in class and thus reduce the dropout rate. Traditionally, tutoring activities have been limited to face-to-face sessions in which students pose questions to the teacher. However, in a connected world with many available information systems, innovative tools are needed to facilitate and speed up both the study and the resolution of doubts in a comfortable way. Methods: This paper proposes using a chatbot based tutoring system as a novel educational experience focused on motivating universities students. Results: Besides, we provide a proof-of-concept implementation of a chatbot that answers questions as quickly and accurately possible at any time, in a comfortable way for the students, and at the same time it gathers feedback from the students regarding those topics that need to be explained in class in more detail. Conclusions: This experience is intended to increase the engagement and collaboration of both students and instructors and has helped to decrease the dropout rate in recent years.
\end{abstract}

Keyword: Chatbot

\section{El uso del chatbot como elemento de acción tutorial en la enseñanza universitaria}

Resumen: Es de vital importancia ayudar y guiar el aprendizaje de los estudiantes a través de diferentes herramientas y actividades educativas que faciliten su participación en clase y permitan reducir la tasa de abandono. Tradicionalmente, las actividades de tutorización para estudiantes universitarios, se limita a reuniones presenciales en las que los estudiantes plantean preguntas al docente. Sin embargo, dadas las circunstancias actuales y ante un mundo conectado con muchos sistemas de información disponibles, se necesitan herramientas docentes innovadoras que faciliten el aprendizaje y una ágil resolución de dudas. Método: en este trabajo se propone la utilización de un sistema de tutorías, basado en el uso de un chatbot como experiencia educativa novedosa y orientada a motivar y facilitar el aprendizaje en estudiantes universitarios. Resultados: estudio aporta la implementación de un chatbot que responde de forma rápida y precisa, disponible en cualquier momento para solucionar dudas y facilitar el estudio de las materias a los estudiantes. Este chatbot además permite recopilar comentarios de los propios estudiantes sobre los temas que requieren ser explicados en clase con un mayor detalle. Conclusiones: El uso del chatbot tutorial, ha permitido aumentar el compromiso y la colaboración tanto de los estudiantes como de los docentes, disminuyendo la tasa del número de estudiantes que abandonan la asignatura.

Palabra clave: Chatbot

\section{Introduction}

Digital technologies, powered by the capacity and reach of the Internet and applied to teaching, have the potential to enhance education at all levels (Littleton and Wegerif, 2003; Twyman and Heward, 2018). In this sense, the technology behind chatbots (Gong, 2018; Bradesko and Mladenic, 2012) has become an usual element in our everyday life, having played an important role in the development of many fields, including education and online tutoring (Clarizia et al, 2018; Smutny and Schreiberova, 2020). These automatic systems ease personalized learning, adapting individuals' pace of learning, who get personalized online tutoring outside the classroom.

A chatbot is a program that allows the machine to communicate in a similar way as a human does (Gong, 2018). This technology is primarily used in customer interaction, website marketing, and instant messaging. However, more and more institutions are 
using chatbots as a helping tool that offers quick answers on different academic issues: administrative or planning questions, about teachers and subjects, or finding courses. This way, students are provided with as much information as possible, at any time, and the communication is facilitated on a regular basis, increasing student engagement (Nguyen, Cannata, and Miller, 2018). Moreover, chatbots can significantly contribute to providing interactive learning experience as well as individual attention (Agarwal and Wadhwa, 2020).

In this sense, chatbot technology offers a great opportunity for the improvement of tutoring systems (Agarwal and Wadhwa, 2020; Daniels, 2016), as not all students are comfortable with face-to-face tutoring with the instructor. In fact, in many cases, students suffer stress when they must ask a question in front of the entire class. Therefore, many students prefer to remain silent and ask their question later via email. However, this means a waste of time and a delay of hours or even days to get the teacher's answer. Chatbot technology has a potential to fill the gap between teacher and students, helping them to solve questions and carry out a dynamic and autonomous learning (Griol, Molina and de Miguel, 2014; Kim, 2020). Moreover, using an automated system such as a chatbot allows the teacher to detect those topics that are most in demand, and on which he or she should consequently place more emphasis in class. However, today the chatbots used in education and reported in the literature are mainly small projects applicable in a very specific scope (Bii, 2013; Kim and Baylor, 2000; Smutny and Schreiberova, 2020).

Thus, in this paper a new chatbot-based tutoring system is presented as a tool to enhance the students' autonomous learning, allowing their interaction using a kind of tool they are used to. Our aim is to create an effective tool for tutorial support, available at any time during the semester, as a help that complements the teacher, and thus improving teacher-student communication. We also offer technical details about both the development of the software and about how to implement it in university teaching. To do so, we employ a design science research approach (Hevner, et al., 2004; Hevner, 2007), entailing designing, building, and evaluating the proposed system. Likewise, we have analyzed the degree of acceptability that the use of this chatbot tutorial system would have by the students participating in this study, using as a theoretical framework the technology acceptance model (TAM) proposed by Davis (1989). This arises to explain why users accept or reject computer technology. Specifically, this model tries to develop and predict the antecedents of the behavior of use of different computer systems and has been successfully applied in different environments, including the academic (AguilarLuzón et al., 2012), so we can consider it a suitable model for the purpose of this study.

In this model considerer that attitudes towards the acceptance of technologies are important elements in their acceptance and identify two determinants of these: beliefs about perceived utility (UP) and perceived ease of use (FUP). The perceived utility of use refers to the expectations that the person has about the improvement in the execution of their work if they use the computer. The other variable included in the TAM is perceived ease of use (FUP), understood as the degree to which a person believes that by using a particular system, they could free themselves from effort, either physical or mental (Davis, 1993). For the TAM, the more useful and easier it is assigned to computer systems, the more positive will be the attitude generated towards them and, therefore, the greater the probability of use.

We expect to enhance student engagement and motivation, to decrease failure and dropout rates, studying the impact that the application of the chatbot in the tutoring system has on academic results (and providing quantitative and qualitative results on how students have interacted with the chatbot). 
Moreover, a proof-of-concept is provided (the chatbot code has been published in a repository in GitHub https://github.com/pacastillo/ChatbotTutoringSystem.git to make it easier for any teacher to integrate it into their teaching activities) and the results of using it in recent university subjects during three academic courses have been reported.

Specifically, the following research questions have been addressed in this paper:

- What improvements, in terms of academic performance and attitude towards the subject by students, can be achieved by introducing chatbots into university teaching?

- Is the proposed tool a suitable tool to complement the teacher's support in tutoring and to provide students with a greater degree of personalized and autonomous learning?

\section{State of the Art}

Conversational programs to facilitate communication between computers and humans using natural language have existed for many years (Thompson, 2007; Shah, et al., 2016). However, those were very limited systems in terms of the capacity of the models used at the time (Hutchens, 1996). Only recently this type of software has been able to use more complex vocabularies and more robust computer models to provide better responses to users (Hoy, 2018; Riel, 2020).

Most of these programs are built from a set of rules or flows designed to answer questions on a specific topic (Agarwal and Wadhwa, 2020). These types of programs are usually built following two main techniques, i.e., recovery-based, and generationbased (Winkler and Söllner, 2018) The first type uses predefined input patterns and responses, and then some heuristics to select the appropriate response. On another hand, generative models are based on the use of machine learning techniques to generate responses out of the input analysing a large amount of data.

In the field of education chatbots have been used for both providing information to the user or facilitating student learning (Agarwal and Wadhwa, 2020; Bii, 2013; Heller et al, 2005; Kerly, Hall, and Bull, 2007). Chatbots can help students and teachers in many ways, e.g., automatically grading questions posed to students, or compiling the highlighted points mentioned by most of the students, and further send it to the teachers, giving them the opportunity to identify gaps in their teaching efforts and improve their classes and explanations (Smutny and Schreiberova, 2020). These systems also allow the students to express themselves freely. Finally, they can provide information about administrative processes, carrying out time-consuming tasks of replying to each query personally in an automatic way and instantly, saving staff and students' time.

Chatbots have been widely used as pedagogical agents to introduce improvements and personalize the teaching (Dutta, 2017; Huang, Kwon and Kim, 2017; Laurillard, 2013). In fact, in recent years more and more companies and educational institutions have introduced them to smoothen their administrative tasks and also to provide personalized information to students (Smutny and Schreiberova, 2020). For example, and regarding educational institutions, Georgia State University launched a chatbot to assist new students and to guide them through their first semester of admission (https://bit.ly/2LAdOiT). Similarly, Lancaster University developed a chatbot to answer questions about schedules, professors and courses (https://bit.ly/2LxxZhB), and the Beckett University implemented a chatbot to help prospective students find the right course (https://bit.ly/2Teuv7J). Regarding companies, differ designed a chatbot to assist students in higher education, answering questions ranging from general administrative 
questions to more detailed questions about course work expectations (Bettinger et al, 2020; Mattsson and Andersson, 2019). The online learning community Brainly (https://brainly.co) uses a machine learning bot that suggest experts to answer the academic questions posted by students. MyTutor company (https://www.mytutor.co.uk), in collaboration with University College London's Institute of Education, developed an online tutoring site to connect students to their most suitable advisor. Finally, an increasing number of chatbot systems are introduced to give individual student support especially in large-scale learning scenarios, such as massive open online courses (MOOCs) (Hone and El-Said, 2016).

On another hand, in recent years, several authors have carried out studies on the convenience of integrating chatbots in teaching, evaluating their characteristics. Thus, Agarwal and Wadhwa, (2020) studies the existing work on chatbots in academia and report the efectiveness of chatbots to enhance motivation, interaction, and learning. On another hand, Coniam (2014) evaluates several systems, concluding that they are still in an early stage to be used with guarantees. Likewise, Tallyn et al. (2018) evaluates a system related to a very specific topic that is suitable for answering specific questions using a chat. Finally, Smutny and Schreiberova, (2020) present a review study examining the educational chatbots in Facebook Messenger with focus to identify characteristics such as language, subject matter, and platform.

According to Roblyer et al. (2010) using either tools such as mobile devices or teaching strategies based on gamification (Yildirim, 2017) can improve student motivation. In this sense, Pimmer et al. (2019) carried out a series of experiments with technological tools whose results showed positive perception and acceptance of the use of technology in teaching and learning, since students are used to using those media with which they can express themselves freely.

Although chatbots technology has improved in recent years, there is still a need to develop research on how to properly apply it in the field of education, as well as to provide tools easily applicable in different scenarios (Fryer, 2017; Sjostrom et al., 2018; Smutny and Schreiberova, 2020; Winkler and Söllner, 2018).

Therefore, in this paper we develop a new tutoring system, and we provide a proof-ofconcept to facilitate the autonomous learning of students, making it easy for them to interact through a tool they are used to, with the main objective of improving their academic results.

\section{Methodology}

This study is a descriptive case study in which the development and use of chatbots is proposed to enhance the tutoring system used in two university courses. In this section the teaching experience is presented, detailing the subjects in which the students are enrolled, as well as the objectives of the proposal and describing how the chatbot was implemented.

\section{Participants}

The students involved in this experience were from the Bachelor's Degree in Computer Science of the University of Granada (Spain) and they were enrolled in one of the following degree courses:

- Peripherals and Human Interface Devices (Information Systems Specialisation), taught in the sixth semester. 
- High Performance Web Servers (Information Technology Specialisation), taught in the eighth semester (last course).

As stated, these courses are taught in the final semesters of the Bachelor's Degree in Computer Science, so students enrolled have knowledge and skills that allow them to pursue a more autonomous learning. In addition, these students have knowledge of web development, information architecture and server administration, so they could actively participate in the preparation of the question-answer (training dataset). In the same way, they were able to install, configure and use the chatbot both through the web interface as well as locally (installed as a standalone program in the student's personal computer) through the developed graphic interface.

Thus, it is a sample widely experienced in the use and management of computer systems, so the level of knowledge used as a premise in the TAM model, allows us to consider this condition as a constant in the sample.

\section{The educational experience objectives}

The objective of the experiment we have carried out is to involve students in the course from the beginning of the semester. To do so, students participate in the preparation of questions and answers as the theoretical and practical agenda progresses, serving them as a study task, and at the same time, increasing their engagement and interest by feeling that their work is useful for the rest of the group-class. In this way, by carrying out that task, it is expected that the current failure rate will decrease. This failure rate was mainly attributed in previous years to the students' attitude towards the amount of theoretical and practical contents of the subject. As a result, many students skipped classes, and therefore eventually failed the course. The academic objectives of using a chatbot tutoring system are the following:

- Increasing student interest in the course and thus, decrease the failure rate.

- Improving student understanding of theoretical concepts, by participating in the preparation of the training dataset (questions and answers).

- Decreasing dropout rate at the end of the course.

- Implement a tool for tutoring, thus providing with a close and adapted assistance to students at any time during the semester.

As stated, this educational experience has been carried out in two courses (Peripherals and Human Interface Devices, and High-Performance Web Servers) of the Bachelor's Degree in Computer Science of the University of Granada (Spain). These subjects have been taught using the same resources as in previous courses when the proposed tutoring tool was not used. Basic updates of the contents have simply been made in terms of technologies and references, but not in terms of objectives, topics, or practical exercises. Just the use of the chatbot system and the educational tasks related to preparing questions and answers to train the chatbot and improve its answers were changed.

\section{Chatbot development}

As stated above, chatbots are usually built following either recovery-based or generationbased techniques (Agarwal and Wadhwa, 2020). The first type uses some heuristics to select the appropriate response considering a predefined input set of patterns and responses. This kind is widely used to make goal-oriented chatbots where we can tune and control the communication between human and chatbot to provide an adequate experience. On the other hand, generative models are based on the use of a large 
amount of data that must be analysed using advanced algorithms such as machinelearning methods to give answers.

In this work, a generation-based chatbot has been designed using deep learning techniques and natural language processing (NLTK) (Faris et al., 2020; Kanan et al., 2019; Ponti et al., 2019). The chatbot will be trained using a data set containing categories (intentions), patterns and answers. A LSTM neural network is used to classify which category the user's message belongs to, and then give to the user one of the available answers in the list of that category (Srinivasa-Desikan, 2018).

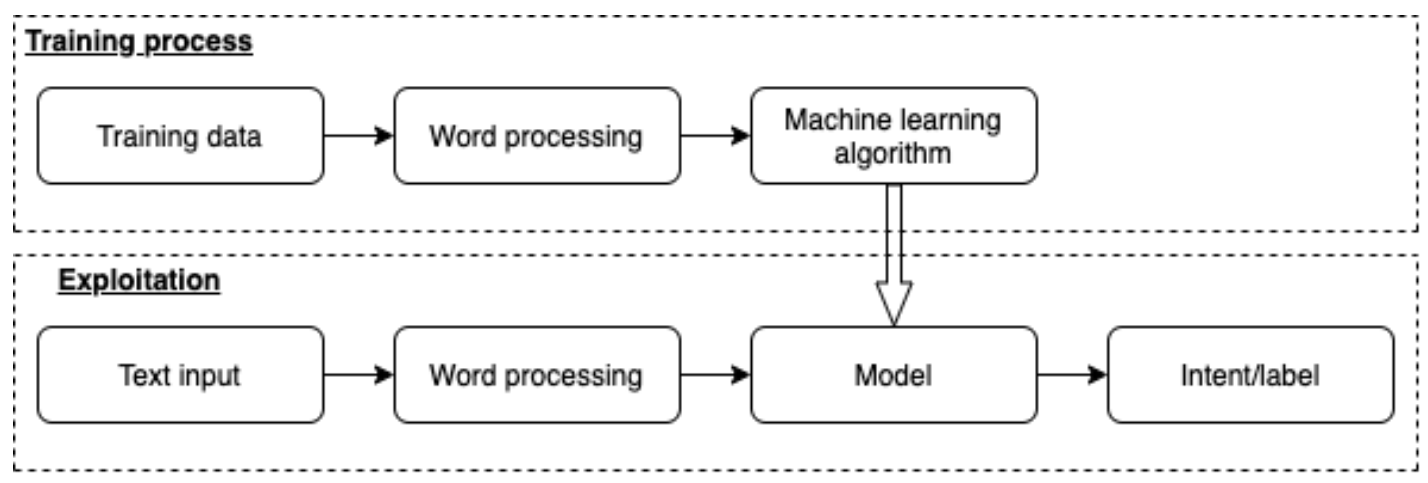

Figure 1: Diagram of the chatbot training and operation processes. In the training phase, a longpredefined dataset of categories, patterns and answers is used to create a suitable model that will be used later in the exploitation phase to generate the responses to the students' queries.

The chatbot receives the student's question and process it to create a set of words. Then, those words are passed as inputs to the trained neural network model that will provide us with a list of intents and their corresponding probabilities (their likelihood of matching the correct intent). In this way, the program shows the student the answer with the highest probability among all the available ones.

Figure 1 shows how the training and exploitation processes of the designed model are carried out. To work properly and give adequate answers, the chatbot needs to be trained using a dataset as complete as possible, containing the patterns we need to find out using the neural network and the answers we want to give to the user. In order to do so, the training data in which we provide the input (pattern) and output (class) to which the input pattern belongs was created from the theory and practice texts (http://mercurio.ugr.es/pedro/docencia/swap) explained in the classes (CastilloValdivieso, 2016 a-b).

The code developed has been adapted from the one published in TEAM (2020) and has been made available to the scientific community in a repository in GitHub (https://github.com/pacastillo/ChatbotTutoringSystem.git). Our aim is that teachers who wish to use this technology to improve their teaching can implement a system similar to the one described in their courses. Figure 2 shows the operation schema of the tool developed and made available to students. 


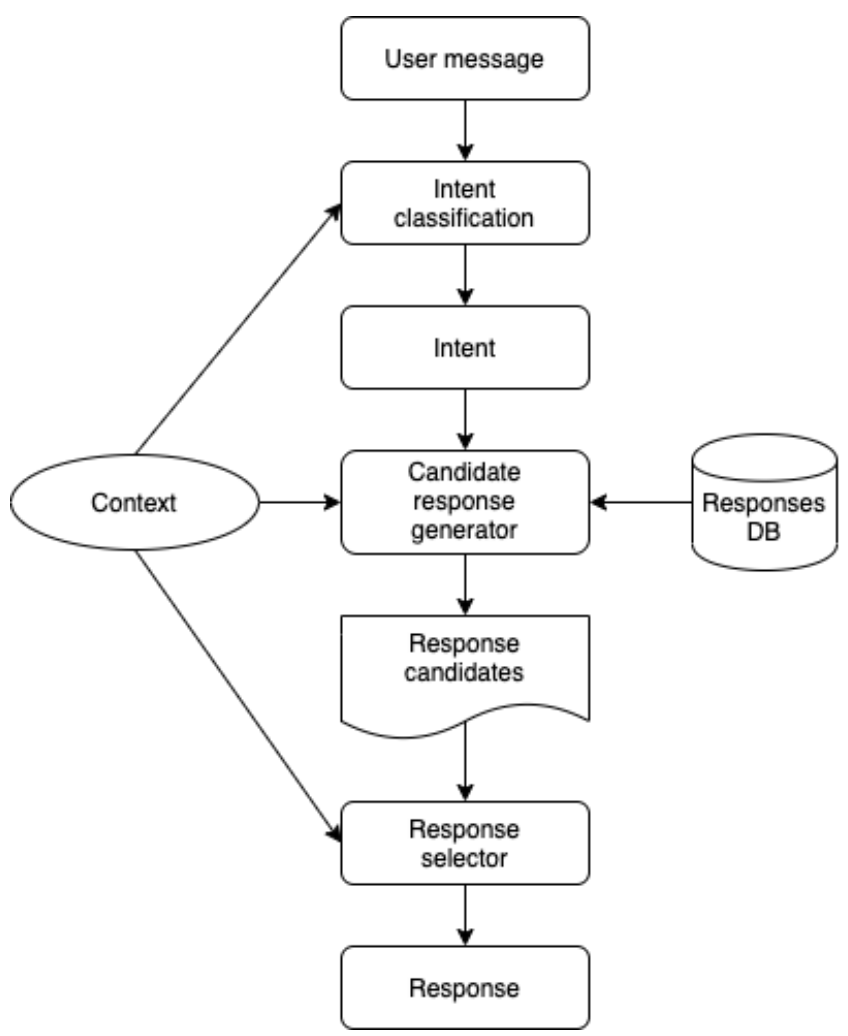

Figure 2: Diagram of the operation of the chatbot developed.

A key part of the development has been the creation of the dataset with the detailed set of input patterns (lists of topics) and possible responses in natural language. As stated above, students participated in this process by studying in groups to propose questions and answers that were later reviewed by the instructors. As an example, in the appendix 1 shows a part of the dataset created to train the model used for the chatbot. The texts used in the theory and practice classes have been carefully included (all the topics in the subjects were collected in the different categories and associated to the corresponding answers), so that the students' queries can be properly answered.

Once the dataset was completed, the training process took the words list in the dataset and turned them into their base meaning. Then, a neural network model was built using the Keras sequential API (Srinivasa-Desikan, 2018). The model architecture is composed by 3 layers: First layer includes 128 neurons; second layer 64 neurons and the output layer contains several neurons equal to number of intents to predict. After intense experimentation training the neural network for 500 learning trials or epochs using stochastic gradient descent (Srinivasa-Desikan, 2018) we achieved 100\% accuracy on our model. The trained model was stored in a file and provided to students to be used with the user-friendly graphical interface of the tutorial system. In this sense, an objective was implementing an interface like those that students usually use in their day to day, so that it is accessible to them, and at the same time we avoid the risk that they do not use the tool provided.

Both a program with a graphical interface that can be used locally and a web interface for access the system through a web browser were developed. Figure 3 shows a full chat session using the graphic interface developed to use the chatbot locally. As the basic chatbot was developed in Python language, to deploy the web service, a small web server written in Python using the socket server package was developed. This way, the chatbot code integrates in a lightweight web service. Figure 4 shows a full chat session using the web interface developed to use the chatbot through a web browser. As it can 
be seen, the chatbot analyses the queries properly to provide an appropriate response and thus solve the doubts raised. During the chat sessions, the highlighted points mentioned by most of the students are saved to a log and sent later to the teacher. In this way the teacher gets feedback to improve his/her teaching efforts, either explaining specific topics in detail in the next classes or offering additional resources to the students to broaden their knowledge in those topics.

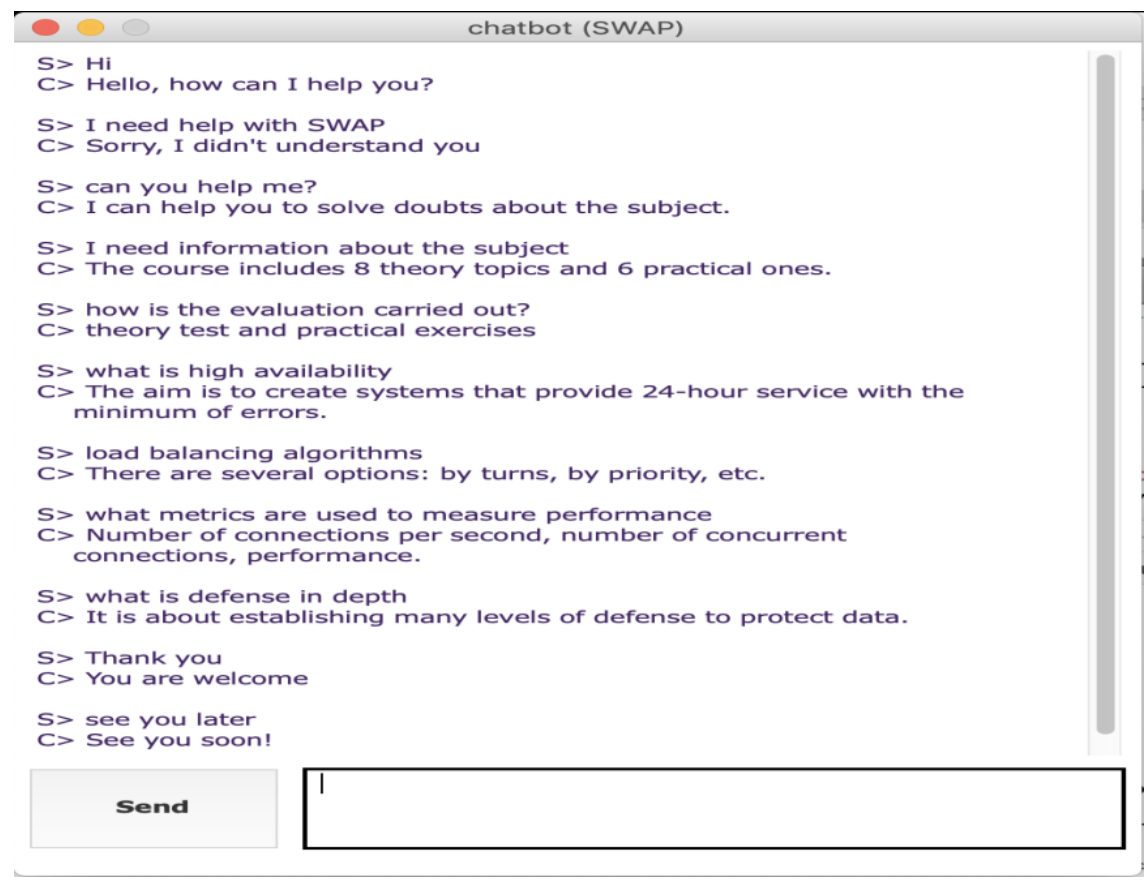

Figure 3: Full chat session between a student and the proposed tutoring support system using the graphic interface developed to use the chatbot locally. Both questions and answers have been translated to English in this example. In the chat session, student interventions are indicated with the $\mathrm{S}$ prompt while chatbot responses are indicated with the C prompt. In this example, the HighPerformance Web Servers chatbot has been used.

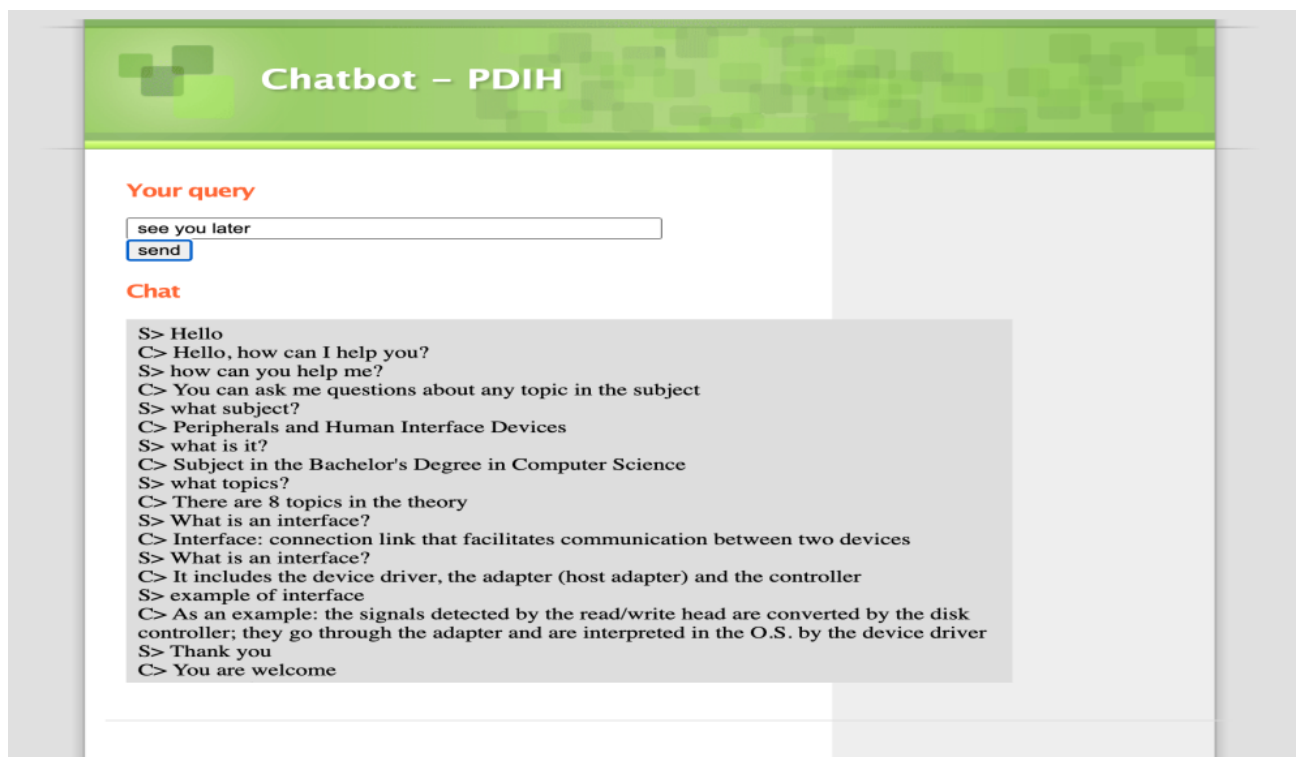

Figure 4: Full chat session between a student and the proposed tutoring support system using the web interface developed to use the chatbot through a web server. Both questions and answers have been translated to English in this example. In the chat session, student interventions are indicated with the S prompt while chatbot responses are indicated with the $\mathrm{C}$ prompt. In this example, the Peripherals and Human Interface Devices chatbot has been used. 


\section{Results}

We have compared the performance of students in two subjects taught without the use chatbots and when they were taught using the chatbots. In the Tables 2 and 3 show the number of students enrolled in each course-offering and the percentage of students passing the course. The experience was first introduced in the 2017-2018 High Performance Web Servers course-offering and in the 2018-2019 Peripherals and Human Interface Devices course-offering, which led in both cases to an increase in the percentage of students who passed the subject:

- from $59 \%$ in $2015-2016$, to $73 \%$ in $2017-2018$ and $78 \%$ in $2018-2019$ (High Performance Web Servers course)

- from 43\% in 2016-2017, to 68\% in 2018-2019 (Peripherals and Human Interface Devices course)

The increase in the percentage of students passing the subjects (see Tables 2 and 3 ) is a direct consequence of the fact that many more students have decided to follow the subjects throughout the semester, having more confidence in passing them after having participated in the development of the chatbot tutoring system and having used it throughout the semester (which helped them to study continuously and constantly).

This demonstrates the importance of being involved in the course throughout the semester and, of using tools that facilitates and increases student engagement and participation.

Next tables show how students used traditional tutorials in previous courses along the semester and compare to the use of the new tutorial tool provided in recent courses.

Table 1

Percentage of students passing the High-Performance Web Servers course over the last four academic years. The pass rate increased in the last two years, after the introduction of the chatbot tutoring system (highlighted in boldface)

\begin{tabular}{|c|c|c|}
\hline Course & Enrolled students & \% Students passing \\
\hline $2015-2016$ & 71 & $59 \%$ \\
\hline $2016-2017$ & 75 & $56 \%$ \\
\hline $\mathbf{2 0 1 7 - 2 0 1 8}$ & $\mathbf{7 2}$ & $\mathbf{7 3 \%}$ \\
\hline $\mathbf{2 0 1 8 - 2 0 1 9}$ & $\mathbf{7 7}$ & $\mathbf{7 8 \%}$ \\
\hline
\end{tabular}

Table 2

Percentage of students passing the Peripherals and Human Interface Devices course over the last three academic years. The pass rate increased in the last year, after the introduction of the chatbot tutoring system (highlighted in boldface).

\begin{tabular}{|c|c|c|}
\hline Course & Enrolled students & \% Students passing \\
\hline $2016-2017$ & 25 & $43 \%$ \\
\hline $2017-2018$ & 24 & $41 \%$ \\
\hline $\mathbf{2 0 1 8 - 2 0 1 9}$ & $\mathbf{2 6}$ & $\mathbf{6 8 \%}$ \\
\hline
\end{tabular}


Table 4

Number of students attending the tutoring sessions and those using the chatbot tutoring system of the High-Performance Web Servers course over the last four academic years. Traditionally, the number of students attending tutoring sessions were low. After the introduction of the chatbot tutoring system the number of students attending tutoring sessions decreased, at the time that many students started to use the chatbot to solve their doubts.

\begin{tabular}{|c|c|c|}
\hline Course & $\begin{array}{c}\text { Number of students } \\
\text { attending tutoring sessions }\end{array}$ & $\begin{array}{c}\text { Number of students using } \\
\text { the chatbot tutoring system }\end{array}$ \\
\hline $2015-2016$ & 24 & - \\
\hline $2016-2017$ & 22 & - \\
\hline $\mathbf{2 0 1 7 - 2 0 1 8}$ & $\mathbf{1 6}$ & $\mathbf{5 5}$ \\
\hline $\mathbf{2 0 1 8 - 2 0 1 9}$ & $\mathbf{1 5}$ & $\mathbf{6 2}$ \\
\hline
\end{tabular}

As it can be seen, using a new tool to teach these subjects and to assist students in tutorial sessions in recent years resulted in an improvement of the results obtained. In previous courses, students used traditional tutorials only a few days before an exam. The use of chatbots to improve the tutorials (and thus assisting students to study) has resulted in a continued tutoring activity during the semester.

Finally, the proposed tool has allowed to collect the list of most frequently consulted topics by students at any time along the semester. In this way, a source of updated information on which topics raised more doubts has been obtained. Thus, the explanations could be improved and more resources to reinforce those topics in classes could be provided.

As an example, next table reports the most frequently consulted topics by students attending Peripherals and Human Interface Devices course over the last academic year.

Table 5

Number of students attending the tutoring sessions and those using the chatbot tutoring system of the Peripherals and Human Interface Devices course over the last three academic years. As in the previous case, traditionally, the number of students attending tutoring sessions were low. After the introduction of the chatbot tutoring system the number of students attending tutoring sessions decreased, at the time that many students started to use the chatbot to solve their doubts.

\begin{tabular}{|c|c|c|}
\hline Course & $\begin{array}{c}\text { Number of students } \\
\text { attending tutoring sessions }\end{array}$ & $\begin{array}{c}\text { Number of students using } \\
\text { the chatbot tutoring system }\end{array}$ \\
\hline $2016-2017$ & 9 & - \\
\hline $2017-2018$ & 10 & - \\
\hline $\mathbf{2 0 1 8 - 2 0 1 9}$ & $\mathbf{6}$ & $\mathbf{1 8}$ \\
\hline
\end{tabular}

Table 6

Most frequently consulted topics by students attending Peripherals and Human Interface Devices course over the last academic year.

\begin{tabular}{|c|l|}
\hline $\begin{array}{c}\text { Number of } \\
\text { queries }\end{array}$ & Topic consulted \\
\hline 24 & Assembler programming \\
\hline 15 & Low level programming \\
\hline 9 & Hardware interfaces \\
\hline 8 & Low level IO management \\
\hline 6 & Arduino programming \\
\hline 5 & Sensors and transducers \\
\hline 4 & Sound processing \\
\hline
\end{tabular}




\section{Assessment of the experience}

To evaluate the experience, a voluntary and anonymous questionnaire was given to the students. The instructors collected 160 completed surveys throughout the three academic courses in which the teaching experience was carried out with the aim of using the student opinions to improve the experience in future years.

The instructors were particularly interested in the students' opinion related to whether the experience had improved their knowledge of the course topics.

Thus, there were three questions, to measure the explanatory variables of chatbot use behavior, according to the TAM model (Bagozzi, Davis and Warshaw, 1992). Student were asked to respond to each item on a 5-point Likert -type scale from (1) indicating "Not at all" to (5), indicating "Strongly agree". The first item, (Q1) measures the degree of perception of students about the usefulness of using the chatbot for learning the contents of the subject. A second item (Q2) was relative to the perceived ease of use (FUP), regarding the degree to which they thought it would be easy for them to use the chatbot to help them solve their doubts and to understand the theoretical concepts. And a third item (Q3) was whether the queries made to the chatbot would have been made to the teacher if he or she had not had access to the new tutoring system.

Once the data was collected, we performed an analysis of the average scores for each item, to find out which aspect was the most important for the students regarding the use of the chatbot. The results found indicate that the main characteristic that stands out is the fact of perceiving that the tutoring system through the chatbot has a high utility $(\bar{X}=$ $3.4312)$ for the study of the contents of the subject, followed by the perceived ease of use $(\bar{X}=3.325)$. We must bear in mind that the students with whom the use of this tutoring system has been put to the test have extensive experience in the management of computer systems, so these results should be interpreted with some caution. The average score obtained with the third item $(\bar{X}=2.65)$ confirms that the fact of participating in this tutoring experience is valued by the students and has made it easier for them to make inquiries and resolve doubts.

\section{Conclusions and future work}

In recent years several tools based on computer algorithms are taking on greater importance in education (Littleton, and Wegerif, 2003; Zawacki-Richter, et al, 2019) and specifically in tutoring activities, providing methods of customization, and improving the quality of services provided through data analysis. In this sense, tutoring bots may have a promising future in the coming years, as their integration into educational environments is an increasing need.

This paper describes a novel educational activity and experience conducted during three academic courses to counter student apathy and lack of involvement. The experience objectives defined were achieved and correlated with the improvement of academic results.

Obtained results support the idea that the chatbot can be seen as a helper tool that complements the teacher rather than something that can replace him or her completely. Moreover, the proposed tool has had a positive impact on learning and student satisfaction. In the most cases students understood using the new tool improved their learning experience. In addition, the tool has been useful for the students, having helped them to prepare the subjects. It has also meant an improvement in the tutorial assistance 
to the students, who have felt freer to make consultations (otherwise they probably would not have raised them).

Finally, as an improvement for future courses, several students suggested that the tool should be used as an additional tool, but that face-to-face tutoring and personal support should not be suppressed. It was also suggested that the experience should be carried out in subjects from other courses and other degrees.

The teaching experience presented has been carried out in two subjects of the last semesters of the Bachelor's Degree in Computer Science, so the students enrolled have knowledge and skills enough to carry out a more autonomous training. In any case, obtained results encourage instructors to continue using the proposed tutoring system in the future and to implement it in other subjects and degrees.

Finally, for readers with similar objectives, it is very important to create an adequate knowledge base to train the chatbot to obtain the desired results. Thus, as future work we intend to improve the training dataset, including as many answers as possible to any question related to the subjects, so the chatbot gives the most accurate answers. In addition, a very interesting line to explore will be the use of several chatbots with different roles that analyse the questions posed by the students from several points of view and thus cover different aspects of the learning process (Hayashi, 2014). We believe that, given the current circumstances arising from the pandemic situation and which have led to the implantation of online teaching systems as the usual way of teaching classes, this work may represent an advance in the use of online tutoring systems.

\section{References}

Agarwal, R, \& Wadhwa, M (2020). Review of state-of-the-art design techniques for chatbots. SN Computer Science, 1, 246.

Aguilar-Luzon, MC, Berrios, P, \& Lopez-Zafra, E (2012) The use of computer systems in the study of university subjects: Applying the theory of planned behavior and the theory of technology acceptance. Studies in Psychology, 33(2), 179-190.

Bagozzi, RP, Davis, FD, \& Warshaw, PR (1992). Development and test of a theory of technological learning and usage. Human Relations, 45, 659-686.

Bettinger, E, Fairlie, RW, Kapuza, A, Kardanova, E, Loyalka, P, \& Zakharov, A (2020). Does edtech substitute for traditional learning? experimental estimates of the educational production function. Working Paper 26967, National Bureau of Economic Research.

Bii, P (2013). Chatbot technology: A possible means of unlocking student potential to learn how to learn. Educational Research, 4(2), 218-221.

Bradesko, L, \& Mladenic, D (2012). A survey of chabot systems through a loebner prize competition. Res Net, 2, 1-4.

Castillo-Valdivieso, PA (2016b). Material Didáctico para el Diseño de Servidores Web de Altas Prestaciones. Editorial Técnica Avicam.

Castillo-Valdivieso, PA (2016a). Diseño de Prestaciones. Editorial Técnica Avicam.

Clarizia, F, Colace, F, Lombardi, M, Pascale, F, \& Santaniello, D (2018). Chatbot: An education support system for student. In
Castiglione, A, Pop, F, Ficco, M, \& Palmieri, F, editors, Cyberspace Safety and Security, 291-302, Cham. Springer International Publishing.

Coniam, D (2014). The linguistic accuracy of chatbots: usability from an ESL perspective. Text \& Talk, 34(5), 545-567.

Daniels, H (2016). Vygotsky and pedagogy. London: Routledge.

Davis, FD (1989). Perceived usefulness, perceived ease of use and user acceptance of information technology. MS Quartely, 13, 319340

Davis, FD (1993). User acceptance of computer technology: system characteristics, user perceptions. International Journal ManMachine Studies, 38(3), 475-87.

Dutta, D (2017). Developing an intelligent chat-bot tool to assist high school students for learning general knowledge subjects. Georgia Institute of Technology. Atlanta.

Faris, H, Aljarah, I, Habib, M, \& Castillo, PA (2020). Hate speech detection using word embedding and deep learning in the arabic language context. In Marsico, MD, di Baja, GS, \& Fred, ALN, editors, Proceedings of the 9th International Conference on Pattern Recognition Applications and Methods, ICPRAM 2020, Valletta, Malta, February 22-24, 2020, 453-460. SCITEPRESS.

Fryer, LK, Ainley, M, Thompson, A, Gibson, A, \& Sherlock, Z (2017). Stimulating and sustaining interest in a language course: An 
experimental comparison of chatbot and human task partners. Computers in Human Behavior, 75, 461-468.

Gong, $L$ (2008). How social is social responses to computers? the function of the degree of anthropomorphism in computer representations. Computers in Human Behavior, 24(4), 1494-1509.

Griol, D, Molina, J, \& de Miguel, A (2014). The geranium system: Multimodal conversational agents for e-learning. Distributed Computing and Artificial Intelligence, 11th International Conference, 290, 219-226.

Hayashi, Y (2014). Togetherness: Multiple pedagogical conversational agents as companions in collaborative learning. In $\mathrm{K}$ TrausanMatu et al. (Eds.), Intelligent Tutoring Systems (ITS2014). Berlin: Springer-Verlag Berlin, 8474:114-123.

Heller, B, Proctor, M, Mah, D, Jewell, L, \& Cheung, B. (2005). Freudbot: An investigation of chatbot technology in distance education. In Kommers, P. and Richards, G., editors, Proceedings of EdMedia + Innovate Learning 2005, pages 3913-3918, Montreal, Canada. Association for the Advancement of Computing in Education (AACE)

Hevner, A (2007). A three cycle view of design science research. Scandinavian Journal of Information Systems, 19

Hevner, A, March, S, Park, J, \& Ram, S. (2004). Design science in information systems research. MIS Quarterly, 28(1), 75-105.

Hone, KS, \& El-Said, G. R. (2016). Exploring the factors affecting mooc retention: A survey study. Computers \& Education, 98, 157168

Hoy, MB (2018). Alexa, Siri, Cortana, and more: An introduction to voice assistants. Medical reference services quarterly, 37, 81-88.

Huang, J, Kwon, KLO, \& Kim, Y (2017). A chatbot for a dialoguebased second language learning system. CALL in a climate of change: adapting to turbulent global conditions: 151

Hutchens, JL (1996). How to pass the turing test by cheating. School of Electrical, Electronic and Computer Engineering research report TR97-05. Perth: University of Western Australia.

Kanan, T, Sadaqa, O, Aldajeh, A, Alshwabka, H, AL-dolime, W, AlZubi, S, Elbes, M, Hawashin, B, \& Alia, MA (2019). A review of natural language processing and machine learning tools used to analyze arabic social media. In IEEE Jordan International Joint Conference on Electrical Engineering and Information Technology (JEEIT), pages 622-628.

Kerly, A, Hall, P, \& Bull, S (2007). Bringing chatbots into education: Towards natural language negotiation of open learner models. Knowledge-Based Systems, 20(2), 177-185. Al 2006.

Kim, HY (2020). More than tools: Emergence of meaning through technology enriched interactions in classrooms. International Journal of Educational Research, 100, 101-543.

Kim, HY, \& Baylor, A (2000). Research-based design of pedagogical agent roles: a review, progress, and recommendations. International Journal of Artificial Intelligence Education, 26(1), 160-169.

Laurillard, D (2013). Rethinking university teaching: A conversational framework for the effective use of learning technologies. Routledge.
Littleton, K, \& Wegerif, R. (2003). Special issue on deliberation with computers: exploring the distinctive contribution of new technologies to collaborative thinking and learning. International Journal of Educational Research, 39(8):787 - 791.

Mattsson, L. G. and Andersson, P (2019). Private-public interaction in public service innovation processes-business model challenges for a start-up edtech firm. Journal of Business and Industrial Marketing, 34(5), 1106-1118

Nguyen, TD, Cannata, M, \& Miller, J (2018). Understanding student behavioral engagement: Importance of student interaction with peers and teachers. The Journal of Educational Research, 111(2), 163-174.

Pimmer, C, Bruhlmann, F, Odetola, TD, Oluwasola, DO, Dipeolu, O, \& Ajuwon, AJ (2019). Facilitating professional mobile learning communities with instant messaging. Computers \& Education, 128, 102-112.

Ponti, EM, O'Horan, H, Berzak, Y, Vulic, I, Reichart, R, Poibeau, T, Shutova, E, \& Korhonen, A (2019). Modeling language variation and universals: A survey on typological linguistics for natural language processing. Computational Linguistics, 45(3), 559-601.

Riel, J (2020). Essential features and critical issues with educational chatbots: Toward personalized learning via digital agents. In M. Khosrow-Pour (Ed.), Handbook of Research on Modern Educational Technologies, Applications, and Management. Hershey, PA: IGI Global.

Roblyer, M, McDaniel, M, Webb, M, Herman, J, \& Witty, JV (2010). Findings on facebook in higher education: A comparison of college faculty and student uses and perceptions of social networking sites. The Internet and Higher Education, 13(3), 134-140.

Shah, H, Warwick, K, Vallverdu, J, \& Wu, D (2016). Can machines talk? comparison of eliza with modern dialogue systems. Computers in Human Behavior, 58, 278-295.

Sjostrom, J, Aghaee, N, Dahlin, M, \& Agerfalk, P (2018). Designing chatbots for higher education practice. Proceedings of the 2018 AIS SIGED International Conference on Information Systems Education and Research, page 4

Smutny, P, \& Schreiberova, P (2020). Chatbots for learning: A review of educational chatbots for the facebook messenger. Computers \& Education, 151, 103862

Srinivasa-Desikan, B (2018). Natural Language Processing and Computational Linguistics: A practical guide to text analysis with Python, Gensim, spaCy, and Keras. Packt Publishing.

Tallyn, E, Fried, H, Gianni, R, Isard, A, \& Speed, C (2018). The ethnobot: Gathering ethnographies in the age of iot. In Proceedings of the $2018 \mathrm{CHI}$ Conference on Human Factors in Computing Systems, CHI18, pages 1-13, New York, NY, USA. Association for Computing Machinery.

TEAM, D (2020). Python chatbot project. learn to build your first chatbot using nltk and keras.

Thompson, C (2007). Conversation between two robots' drifts into flirtation and philosophy. discover magazine. Computers in Human Behavior, 29, 845-857.

Twyman, JS, \& Heward, WL (2018). How to improve student learning in every classroom now. International Journal of Educational Research, 87, 78-90. 
Winkler, R, \& Söllner, M (2018). Unleashing the potential of chatbots in education: A state-of-the-art analysis. In Academy of Management Annual Meeting (AOM)

Yildirim, I (2017). The effects of gamification-based teaching practices on student achievement and students' attitudes toward lessons. The Internet and Higher Education, 33, 86-92.
Zawacki-Richter, O, Marín, VI, Bond, M et al (2019). Systematic review of research on artificial intelligence applications in higher education - where are the educators?. Int J Educ Technol High Educ, 16, 39

\section{Appendix 1}

Contents of the dataset created to train the model used for the chatbot (extract).

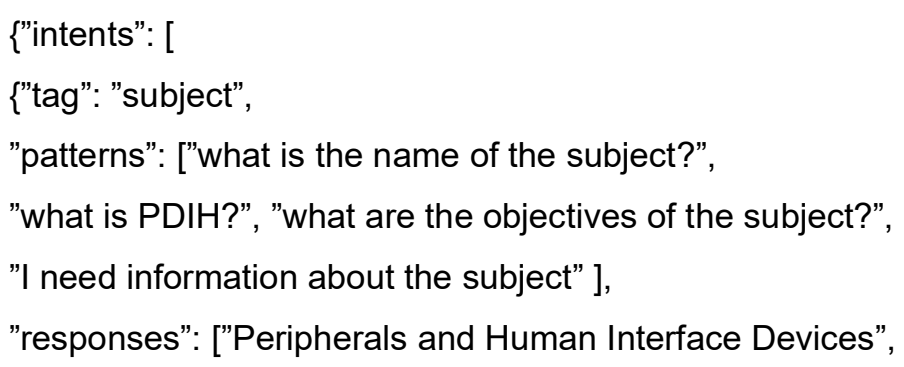

"A subject of the Information Systems Specialisation", "Subject in the Bachelor's Degree in Computer Science", "Defining the concept of a peripheral device",

"Global vision of the concept of peripheral and how it interacts with the CPU and memory"],

\} ,

$\cdots$

$\cdots$

\{"tag": "topic3",

"patterns": ["What is an interface?", "What is included in an interface?" ], "responses": ["Interface: connection link that

facilitates communication between two devices.",

"It includes the device driver, the adapter

(host adapter) and the controller",

"As an example: the signals detected by the read/write head

are converted by the disk controller; they go through

the adapter and are interpreted in the O.S. by the device driver."],

\}

$\cdots$

$\cdots$

]\} 